\section{Michel Maffesoli e a cidade partilhada}

\section{RESUMO}

0 presente artigo tenta mostrar a importância do olhar social de Michel Maffesoli. Indicamos algumas de suas contribuições também para as pesquisas acadêmicas, as quais nos ajudam a chegar mais próximo ao objeto estudado. 0 pensamento maffesoliniano nos permite ainda outro modo de observar 0 mundo e as ações a nossa volta. É basicamente isto que discutimos a seguir.

\section{ABSTRACT}

This paper tries to show the importance of Michel Maffesoli's social views for academic researches on social communication, for they allow us to see the world from another perspective.

\section{PALAVRAS-CHAVE (KEY WORDS)}

- Socialidade (Sociality)

- Pós-Modernidade (Post-modernity)

- "Arquitetura Cultural" (Cultural Architecture)

João Maia

FCS - UERJ
FAZ uM вом теMPO que Michel Maffesoli nos alerta, em diversas obras, que testemunhamos a "temática do espaço" assumir lugar de destaque em vários setores da sociedade (1979). Para o autor existe uma sinergia entre "o espaço e a sociabilidade" criando um mundo original pela relação que a pessoa estabelece com o outro. Este mundo, em permanente formação, é visto pelo autor como um conjunto de referências partilhado entre os homens. As inter-relações com suas atrações e repulsas, em um jogo de forças constantes, gera a "socialidade" pela confiança e aliança solidificando as estruturas sociais. $\mathrm{O}$ ato de admirar o "compartilhar" do espaço da cidade ganha forte significado, em seu pensamento, por ser uma forma de conhecimento. Isso nos leva a refletir sobre os métodos que usamos para se estudar as metrópoles construídas a partir dos jogos interacionais, elaboradas a partir dos encontros banais entre os indivíduos, enfim, pelos cidadãos que tecem histórias cotidianamente. Conhecimento e ação podem não estar sedimentados em relações de hierarquias rígidas, mas criam história.

A "socialidade" para Maffesoli (1988, p. 93) pode ser caracterizada pelo relativismo do viver, pelo dado de grandeza e de trágico contidos no cotidiano. Não podemos esquecer da importância do mundano na formação de nossas sociedades. As nossas pesquisas acadêmicas modernas sempre privilegiaram o caráter "ótico" em suas metodologias. Uma visão distante que olhava o mundo em desenvolvimentos certeiros e constantes e desta forma marcava o "progressismo" de uma época. Hoje, porém, com o apoio de Michel Maffesoli podemos assumir a postura generosa de chegarmos perto de nosso objeto de pesquisa em constante movimento. Podemos não só ver e analisar de maneira distante os fatos 
que constituem o social, mas além dessa postura, nos permitimos "tocar" e "penetrar" o objeto para compreender o homem em suas diversas modulações, atitudes e humores. Metodologicamente o autor revela o caráter "tátil" que se requisita na construção de qualquer objeto de pesquisa na sociedade contemporânea. O fator da "proxemia" nos ajuda a compreender o localismo que se modela cotidianamente. O sensível é como uma marca da cultura (Maffesoli, 1990).

O autor elabora uma "arquitetura cultural" para exibir a maneira pela qual podemos falar da formação da cidade com o outro e também de sua dimensão comunicativa e intersubjetiva. A comunicação transforma-se em comunhão na efervescência das tribos urbanas pelo seu "fechamento" e também, podemos afirmar, pela circulação de códigos e signos que suscita. Nessa arquitetura, existe a solidificação da base, a sustentação, que pode ser entendida como uma verdadeira "centralidade subterrânea" pela "multiplicidade de redes que engendra a ordem simbólica em canais sutis, porém sólidos" (1988. p. 63).

A multiplicidade de "redes", tendo como elemento constitutivo os processos de "interindividualidade", nos impulsiona a dar cada vez mais importância, em nossas análises sobre o social contemporâneo, ao campo da cultura como um lugar de resistência aos domínios de homens que querem ou mesmo sonham em se tornar hegemônicos politicamente.

Podemos ver claramente este pensamento maffesoliniano se estabelecer solidamente e diariamente nas megalópolis. Estas cidades, com características especiais, com signos em constante ebulição, são constituídas por "espaços de celebração" onde se desenvolvem diversos cultos com forte coeficiente estético-ético. As celebrações podem girar em torno do corpo, do sexo, da imagem, da amizade, da comédia, do esporte, mas o importante é que o sentimento de pertença local se afirma diante de signos globais. Nas celebrações, a banalida- de cotidiana vem alimentar os iniciados que comemoram os mistérios. $\mathrm{Na}$ "chopada" no bar da esquina, no batuque da praia ou no churrasco no quintal da vizinha, os lugares serão marcados pela nossa presença.

Este charme dos lugares ou esta energia emanando de determinados locais e que pode circular em bairros específicos produz a vontade de se preservar todos os acontecimentos locais, por mais banais que possam ser considerados. Algumas datas, ou mesmo períodos do ano, serão marcadas por fatos até bem desconhecidos pelo mundo como um todo, mas garantem a piada por um tempo em um determinado lugar. Assim, a micro história será levada em consideração nas diversas interpretações que fazemos das cidades.

Os textos em forma de depoimentos pessoais sobre um verão muito especial no Rio de Janeiro, que marcou a cidade, circulam pela internet. Foi um fato pitoresco, único, inventado ou não, mas ganhou dimensões surpreendentes, chegando a marcar a identidade de um determinado verão carioca. Um desses depoimentos sobre este verão que circulam pela rede é o seguinte:

Se você esteve em outro planeta durante o ano de 1987, provavelmente ainda não escutou a história das latas. Em novembro deste ano, um navio chamado "Solana Star" com um carregamento de 15.000 latas de maconha (pesando 1,25 Kg cada) procedente da Indonésia, passava alegremente pelo litoral do Brasil em direção aos Estados Unidos. Seus tripulantes ficaram então sabendo - não se sabe bem como - que policiais brasileiros e agentes do DEA (Drug Enforcement Agency) americano estavam prontos para interceptar o carregamento. Temerosos de serem presos, os tripulantes jogaram toda a carga no mar a umas 100 milhas da costa e penetraram sorrateiramente no porto do Rio de Janeiro durante a noite, onde aban- 
donaram o navio. $\mathrm{O}$ único que sobrou foi o cozinheiro, que foi prontamente detido pelas autoridades. Durante várias semanas, latas do material foram lançadas contra as praias brasileiras no litoral entre Espírito Santo a Santa Catarina (www.tecepe.com.br/bike/ latas2.htm).

A cidade compartilhada cria, inventa e produz histórias que caracterizam o local e neste verão especial de 1987, quando apareceram boiando em diversas praias as latas contendo uma maconha muito potente, a representação da cidade ganhou uma dimensão inusitada. Este verão ficou conhecido como "o verão da lata".

Até hoje a expressão "da lata" é sinônimo de algo bom, numa referência à boa qualidade do material contido naquelas Latas.

Uma destas coisas engraçadas que não acontecem todos os dias. Jô Soares escreveu em uma crônica na Veja que 87 não seria lembrado por nenhum acontecimento político, econômico ou esportivo: seria lembrado como o ano das Latas (www.naufra giosdobrasil.com.br)

Para Maffesoli, os lugares onde se celebram diversos cultos podem ser considerados como "hauts lieux". Segundo o autor esses lugares se tornam pontos que unem as pessoas que ali circulam. As emoções partilhadas e consolidadas são vividas como fatos constituídos por e para as "tribos" que inscreveram suas histórias neste lugar.

Os "Haut Lieux" são consolidados em diferentes tempos, por "espíritos" diversos que marcaram este espaço. Maffesoli indica que se pode constatar a multiplicidade de pequenos "hauts lieux" através de suas minúsculas celebrações dentro de uma mesma cidade. Em Paris, ele localiza como "hauts lieux" o artístico do Beaubourg, o lúdico do Le Palace e o musical de Bercy.
É evidente que poderíamos denominar ou adjetivar alguns lugares que emanam uma "espécie de alma" chamando a atenção de todos. As justificativas ou explicações não são suficientes para explicar o desejo de se viver intensamente os encontros entre os homens, sem razão concreta, sem objetivos. Algumas vezes alguns desses lugares se tornam mais excitados, mais iluminados ou mais freqüentados. No Rio de Janeiro não faltam exemplos de "Haus Lieux". Podemos listar alguns desses lugares de grande expressão cultural. O imaginário de festa permanente da Lapa, no centro da cidade; a pluralidade e encanto de Copacabana, cantada como "Princesinha do Mar", na zona sul, especialmente na época do final do ano com a grande festa de Reveillon, e também são marcante os encontros cotidianos das diversas tribos da conhecida praia de Ipanema, por onde circulou a famosa garota que virou musa para a canção traduzida em várias línguas pelo mundo. Esses são pontos de referência não apenas para o carioca, mas para todo o mundo. $\mathrm{O}$ que especialmente chama a atenção dos homens para esses lugares? Podemos afirmar que a resposta se concentra na capacidade de aglutinação que esses lugares possuem. Eles têm um certo "espírito" que a todos contamina.

Quando Maffesoli diz que o mundo é um conjunto de referências que eu partilho com outros está enobrecendo a força da sociabilidade que costura firmemente as redes de solidariedade que solidificam as estruturas culturais. Estas estruturas de conjunto são compostas hoje pelo sensível, que por muito tempo foi negligenciado, reaparecendo de maneira intensa no cotidiano da vida social.

O autor pensa a partir da lógica do doméstico que valoriza a "organicidade" da rede e que forma a "unicidade em pontilhado" para criar uma sociologia que privilegia o cotidiano. Esta forma de unidade é composta de relações abertas, efêmeras e emocionais, e é assim, desta forma, que os grupos formam novos territórios. No interi- 
or desta "unicidade" se podem vislumbrar as associações comunitárias requisitando um "familialismo" que tem por base uma dose de acomodação, que não é necessariamente inércia, mas que valoriza a experiência do aqui e agora.

Maffesoli mostra a nossa capacidade de produzir um "curto-circuito" no tempo e no espaço através da comunicação. Ocupamos um espaço material (ruas, monumentos, trânsito) e também imaterial a partir das imagens de diversas ordens. Nestes dois pontos cria-se a "ordem do simbólico" (1990, p. 87). A circulação das informações, das coisas, das palavras e de tudo aquilo que compõe a comunicação, como proxemia, é vital para se compreender a elaboração da cidade e mesmo do bairro. A comunicação é, antes de qualquer outra coisa, como já mencionamos anteriormente, comunhão.

A representação da cidade se torna uma arte de representar uma ilusão criada em comunhão. Pode se dizer que é uma ilusão original quando se inscreve em um lugar determinado e cria uma "história" para servir de suporte à existência dos seus habitantes. $\mathrm{O}$ imaginário de origem, por exemplo, é esta ilusão original. Com a indeterminação do signo que circula na contemporaneidade existe a possibilidade de criação de imagens plurais. Assistimos à criação de um mundo.

\section{- universo simbólico em expansão}

Berger e Luckman são autores que convidaremos para dialogar teoricamente, de maneira próxima, com Maffesoli, para compreendermos alguns percursos de seu pensamento. Esses autores também servirão de suporte para a leitura que fazemos sobre a compreensão da cidade contemporânea a partir do "domínio do simbólico". A cada vez que se observa o fenômeno humano, penetra-se no "reino social". A ordem social, desta maneira, existe como produto da atividade do homem. Os autores desenvol- vem a teoria da institucionalização como ponto de partida na obra $A$ construção social da realidade (1992).

Temos o nosso "estoque geral de conhecimento" composto de elementos disponíveis e pressupostos diante de nossos olhos, inscritos no cotidiano de nossas vidas. Desta forma, a institucionalização se manifesta quando uma classe de atores sociais efetua uma tipificação recíproca de ações consideradas habituais e sempre partilhadas, isto é, quando os indivíduos reconhecem os fatos que estão acontecendo de maneira familiar. As instituições mostram a historicidade e o controle, segundo os autores, pois são construídas ao longo da história partilhada.

Tipificações e "habitualizações" prováveis se mostram, por exemplo, com o trabalho, a sexualidade e a territorialidade. Estas instituições fornecem uma realidade própria, podendo ser transformadas a partir da consciência. No momento do processo da transmissão para a geração seguinte destas instituições a transformação é possível, porém ao mesmo tempo constatamos um mundo mais real sem possibilidade de ser transformado de maneira instantânea. Objetivamente, o mundo será transmitido à geração seguinte.

$\mathrm{O}$ "mundo objetivo" é persistente e sua realidade não permite que se escape da coerção, mas não podemos esquecer que, concomitantemente a esta inércia, mudanças ocorrem o tempo todo. Uma relação dialética se coloca neste processo. $\mathrm{O}$ mundo está diante do sujeito produzindo uma interação e o produto desta relação atua sobre este mesmo sujeito. Desta forma o indivíduo (moi) se transformará nesta relação dialética.

Na geração seguinte vemos esta realidade como tradição e não mais como biografia. As instituições transmitidas possuem autoridade sobre os indivíduos, mas esse fato não significa que eles não possam pensar sobre suas próprias biografias. Os indivíduos tendem a partilhar sua significação do mundo com o outro, estabelecen- 
do uma integração. Assim, Berger e Luckman pensam sobre esta reciprocidade significante dos processos de instituição.

A lógica das instituições tem sua origem na maneira como ela é pensada reflexivamente. $\mathrm{O}$ homem dentro da instituição faz biografia. Os acontecimentos estão ligados a um universo subjetivamente significante para o homem e compartilhados com os outros.

O conjunto de conhecimento é adquirido como realidade objetiva na interação digerida como realidade subjetiva. Esta experiência está incrustada na biografia do indivíduo. As significações socialmente disponíveis objetivarão um segmento de nosso eu (moi) como social, porém distinto do eu em sua totalidade. Joga-se com papéis sociais de acordo com determinada situação para se participar de um mundo social. Quando se aceita um papel o mundo se torna subjetivamente real.

Os papéis permitem representar as instituições como uma presença real na experiência dos indivíduos. Desta maneira, os atores sociais indicam que a representação de uma instituição através dos papéis é a representação por excelência. É evidente que certos papéis, mais do que outros, representam simbolicamente esta ordem em sua totalidade. Os indivíduos jogando com os papéis se encontram diante de um conhecimento socialmente objetivado de normas, de valores e de emoções. Os indivíduos concentrados em suas próprias experiências acumularão um conhecimento específico de determinados locais, de territórios específicos.

Diremos, primeiramente, que as instituições são reais a partir do momento que são realizadas pelos papéis e, em seguida, afirmaremos que os papéis são representativos de uma instituição que, em retorno, define seu caráter. Berger e Luckmam criam "fantasmas sociológicos estimulantes". Imaginam duas sociedades radicais. De um lado uma sociedade onde a institucionalização é total e de outro lado, uma outra sociedade, onde praticamente não existe um "estoque de conhecimento comum".

É evidente que se vive em nossas cidades transformações notáveis nas esferas das significações institucionais através dos desvios crescentes em relação ao modelo heurístico. Apreciam-se especificações de papéis que tornam impossível a integração total das significações nas cidades contemporâneas e ao mesmo tempo vemos, de um lado subjetivo, a dificuldade de harmonizar o sentido que cada indivíduo dá a sua própria biografia atrelado ao sentido que lhe é atribuído pela sociedade.

$\mathrm{Na}$ modernidade, com a divisão do trabalho, surge a possibilidade da existência de "subuniversos" (Schultz:1987, p. 134) compartimentados de significações. O conhecimento específico, neste caso, se torna problemático e oposto ao "estoque comum de conhecimento". Um grupo particular sustentará a significação de certa realidade objetiva criada por eles. Assim, os "subuniversos" de significação de vários tipos se tornam correntes, fluidos e fragmentados em nossas cidades.

A crescente pluralidade de "tribos" urbanas expõe a variedade de perspectivas sobre o mundo e algumas vezes assistimos às significações específicas de cada grupo se chocando e se entrecruzando. O problema que se coloca se pensarmos em termos de metodologia de pesquisa no campo da comunicação e cultura está concentrado na legitimação dos "subuniversos" cada dia mais fragmentados fazendo surgir a diversidade de falas oriundas de lugares nunca dantes observados. O ator social e os pesquisadores devem reconhecer o "subuniverso" como algo de importante e de necessário. A dificuldade de legitimação de certos grupos se torna evidente exatamente pela diversidade. Os autores introduzem a noção de "reificação" da realidade social para pensar a relação do homem com o mundo em fragmentação.

A apreensão dos fatos sociais é nãohumana e supra-humana no pensamento da "reificação" da realidade. $\mathrm{O}$ processo de objetivação do mundo seria maximizado, 
ou seja, o homem se rende à "natureza das coisas". A reificação seria um modo de consciência que o homem possui. Ao mesmo tempo em que ele está produzindo uma realidade, está se negando dentro deste processo. Os papéis que os indivíduos executam dentro do universo "reificado" são também apreendidos como uma coisa inevitável. $\mathrm{O}$ indivíduo se identifica com seu papel e integra sua tribo determinada, ele é esta tribo. Neste processo a biografia do indivíduo deve ter uma significação que torna o mundo subjetivamente plausível. A legitimação diz ao indivíduo por que as coisas são o que elas são. Não é apenas o valor que importa, mas a forma de conhecimento. Assim, na construção social da realidade constroem-se vários níveis de legitimação.

Didaticamente veremos a partir de Berger e Luckman alguns desses níveis de legitimação. O primeiro é o da criança que olha o mundo e entende as respostas aos seus porquês. Este nível constitui o fundamento de um "conhecimento". O segundo nível mostra os esquemas de explicação ligando os conjuntos de significações objetivas. São as explicações dadas sobre as ações concretas. Os provérbios são um exemplo deste nível. O terceiro nível de legitimação é mais especializado. Aqui com os profissionais vemos os direitos, as obrigações e os procedimentos médios em vigor nas instituições. Finalmente chegamos ao quarto nível, que nos interessa especialmente neste trabalho. É o nível dos universos simbólicos.

O universo simbólico é concebido como a matriz de todas as significações socialmente objetivadas e subjetivamente reais. A sociedade histórica inteira e a biografia completa do indivíduo são consideradas como acontecimentos que se realizam no interior deste universo (Berger e Luckman: 1992, p. 133).

Os sonhos e os fantasmas fazem parte deste universo. Assim, um universo inteiro pode se criar. O simbólico fornece a apreensão subjetiva da experiência biográfica. O status soberano da realidade da vida cotidiana acontece graças ao simbólico. Este universo torna possível a integração das realidades diversas (Schultz, 1987).

Podemos dizer que diante da efervescência das tribos urbanas circulando aceleradamente e se intercruzando violentamente, em nossas cidades, recorre-se cada vez mais a este nível de institucionalização para a tarefa de compreender o espaço urbano. É pelo e através do nível simbólico de instituições que podemos falar da construção do cotidiano banal das ruas.

Tendo consciência reflexiva da "sociedade de risco" (Giddens, 1997) em que se vive dada a indeterminação dos fatos na contemporaneidade, somos levados a acreditar que a via do simbólico permite as integrações das significações plurais do cotidiano. Recorrendo ao simbólico pode se criar o sentimento de segurança e pertencimento, pois todos os atos da vida banal, do dia-a-dia, podem ter significado. A partir desta noção de simbólico podemos acreditar que o indivíduo ainda assegura a validade de seus papéis dentro de suas tribos, mesmo que de maneira efêmera.

Até aqui podemos ver em um primeiro grau que o universo simbólico legitima o institucional, de maneira generalizada. Em um segundo grau de legitimação defronta-se com o simbólico a partir de uma teorização. Todas as legitimações podem ser descritas como "mecanismos" servindo à manutenção do universo. Como todo universo simbólico é por definição problemático, encontramos em qualquer ocasião social as tentativas de manutenção deste universo através dos "mecanismos". O universo simbólico é legitimado, mas também é modificado pelos mecanismos que têm a função de defender a sociedade contra os desafios de certos grupos.

Berger e Luckman oferecem, como exemplos de resistências a um desafio, a situação de uma sociedade confrontada 
com uma outra sociedade com uma história diferente. A confrontação de universos diferentes denuncia que este universo não é uma coisa inevitável. A "vitória" dependerá dos mecanismos destinados à manutenção dos universos respectivos.

A mitologia, a teologia, a filosofia e a ciência foram alguns tipos de "mecanismos" conceituais que circularam nos universos. Estes mecanismos ainda estão claros em nossas mentes e não necessitam de grandes explicações ou de exemplos. Basta indicar que com esses "mecanismos" surgiram as resistências, os desvios e as culpabilidades aglutinados em pequenos conjuntos indivíduos para, em grupo, criar uma nova forma de realidade social.

A fragmentação de tribos é constatável no circular pelas ruas das cidades. Os estilos de vida plurais que neste momento estão surgindo mostram verdadeiras "guerras" de forças simbólicas sendo travadas entre grupos nas cidades. Muitas vezes é apenas uma guerra, silenciosa e mansa, travada em campos tranqüilos onde apenas os signos explodem.

\section{O conhecimento partilhado}

A efervescência das relações entre as diversas tribos, como resultante das vivências entre as realidades plurais, evidencia e nos faz recorrer ao dado subjetivo que constitui a vida do dia-a-dia. A questão que levantamos é a de reconhecer a importância do "domínio simbólico" que Michel Maffesoli nos trouxe em suas obras e que, sem dúvidas, nos induziu a trilhar novos caminhos metodológicos em nossas pesquisas no campo da comunicação. Começamos a pensar o nosso "objeto de pesquisa", que motiva uma procura de significação do mundo social, a partir do reconhecimento da existência de uma "pessoa" sensível, de seu destino, de sua realidade e de sua vocação. O fenômeno da "socialidade" investigado por Maffesoli torna possível compreender a participação do homem no mundo.
Quando reconhecemos que a afetividade pontua e marca os fatos significantes de nossas inter-relações cotidianas, o mundo encontra sua estrutura de plausibilidade.

$\mathrm{Na}$ sua obra $\mathrm{O}$ conhecimento comum (1985) Maffesoli reivindica uma sociologia romântica. Um pensamento em oposição à postura determinista da sociologia positivista para abordar o cotidiano. Podemos dizer que o autor trabalha com uma sociologia poética no que concerne à emoção, à vida que vemos, tocamos e sentimos e não pela decodificação do real para validar a significação atribuída aos fatos. Uma sociologia que evidencia o cotidiano, o simbólico, o imediato, o local. A sociologia proposta por Maffesoli sugere a globalidade no interior do fragmento, a integração dentro do objeto de pesquisa, o fato de estarjunto (être ensemble) como participante.

Com esta perspectiva poética da sociologia poderemos analisar, com maior rigor e menor rigidez, o cotidiano da cidade com seus fluxos e refluxos de signos, códigos, mensagens e relatos. Através das categorias tais como "socialidade", "familialismo", "redes" e "hauts lieux" se torna possível tanto deixar a imagem fluida dos diversos imaginários que compõem a cidade como modelar a sua própria representação de cotidiano.

O homem, em seu grupo, assume a cidade como palco de experimentações do domínio do sensível e isso causa certo desconforto para alguns analistas sociais que decretam o fim de um mundo sem perceber o nascimento de um outro. Podemos ver este tipo de pensamento resistente às mudanças se desenvolver em autores que privilegiam, em suas investigações, centradas nas questões do espaço e da sociabilidade, noções como "desterritorialização", "não-lugar" e "deslugares"1.

Alguns pensadores, que pautam suas pesquisas em metodologias que valorizam a "postura ótica" de distanciamento moderno do objeto de pesquisa, esquecem que o homem, em grupo, está permanentemente elaborando novas formas ao seu lu- 
gar de circulação. Já faz muito tempo que a sociedade foi entregue ao homem, para ele mesmo elaborar seus mecanismos de associações. O território, como dissemos anteriormente, não é a simples dimensão material da realidade. Podemos ressaltar, assim, a idéia da existência da criação de uma "multiterritorialidade" ${ }^{2}$ que as "tribos urbanas" planejam, elaboram e ressignificam em suas práticas sociais. $\mathrm{O}$ homem atravessado o tempo todo por diferentes estímulos se torna disperso, distraído e insensível, mas utiliza de seu arsenal simbólico para dar sentido aos seus atos. Este homem contemporâneo necessita de várias máscaras para atuar em um "teatro mundial" (para usar uma expressão de Maffesoli).

Desde Simmel, com sua obra clássica $A$ metrópole e a vida mental, apreende-se o retrato do homem urbano como um indivíduo que necessita se equipar para viver num mundo de trocas aceleradas e de signos múltiplos em rotação. O homem metropolitano moderno se inventou nas "atitudes de reservas" para preservar o mundo interior de invasões externas e violentas. A multiplicidade de códigos circulantes e diferentes supostamente ameaçaria os universos simbólicos, afetivos e domésticos. Seria uma "hiper-realidade" (Baudrillard, 1991) triunfante, com seu caráter pragmático criando hábitos que desconectam e fragmentam a nossa atenção. Com Michel Maffesoli, porém, o mundo se "reencanta" pela valorização da comunicação que é a "correspondência", a "analogia" e a "socialidade".

Vivemos em um espaço plural onde as mudanças fazem parte da natureza. Atribuímos grande importância ao cotidiano e ao imediato, privilegiando, dessa forma, a "solidez das redes" nas interpretações do mundo social. A "socialidade", pelo seu caráter popular, é valorizada pelo "estilo de vida" dos cidadãos comuns e não apenas a partir de noções desenvolvidas no campo da economia e da política que colocavam amarras em suas ações. As transformações culturais revelam um social dinâmico em constante ebulição. A pessoa não vive mais no interior de uma cultura interpretada apenas como um minúsculo elemento constitutivo de uma sociedade moderna. Experimenta-se a cultura do homem comum, na rua, no cotidiano transformando todos os aspectos da vida societária na cidade. Surge, nessa mudança que valoriza o estilo de vida do homem comum, uma mudança de paradigma para se pensar associações diversas. Uma nova cartografia simbólica redesenha a cidade a partir da cultura comunitária, popular, sendo partilhada em diversos saberes •

\section{Notas}

1 Podemos citar alguns autores contemporâneos que colocam em suas obras o debate sobre 0 uso de tais noções. Ver Haesbaert, 2004, Auge, 1994, Ferreira de Melo, 2003.

2 Noção trabalhada por Rogério Haesbaert, 2004.

\section{Referências}

AUGÉ, Marc. Não-lugares: Introdução a uma antropologia da supermodernidade. Campinas, SP: Papirus, 1994.

BAUDRILLARD, Jean. Simulacros e simulações. Lisboa: Relógio D’Água, 1991.

BERGER, Peter e LUCKMAN, Thomas. La construction sociale de la réalité. Paris: Meridiens Klincksieck, 1992.

GIDDENS, Anthony e outros. Modernização reflexiva. São Paulo: Editora da Universidade Estadual Paulista, 1997.

FERREIRA DE MELO, João Baptista. Símbolos dos lugares, dos espaços e dos "deslugares". In: Revista Espaço e Cultura. Número 16. Rio de Janeiro: UERJ, NEPEC, 2003 (pp.6471).

HAESBAERT DA COSTA, Rogério. 0 mito da desterritorialização. Rio de Janeiro: Bertrand Brasil, 2004.

MAFFESOLI, Michel e outros. Espaces et imaginaires. Grenoble: P.U.G., 1979.

MAFFESOLI, Michel. La connaissance ordinaire. Précis de Sociologie 
Compréhensive. Paris: Librarie dês Meridiens, 1985.

MAFFESOLI, Michel. Lêe temps de tribus. Lê déclin de l'individualisme dans les sociétés de masse. Paris: Méridiens Klincksieck, 1988.

MAFFESOLI, Michel. Ética da Estética. Rio de Janeiro: Centro Interdisciplinar de Estudos Contemporâneos/ ECO/ UFRJ, 1988.

MAFFESOLI, Michel. Aux creux dês apparences. Pour une éthique de l'esthétique. Paris: PLON, 1990.

SHULTZ, Alfred. Le chercheur et le quotidien. Paris: Méridiens Klincksieck, 1987. 